\title{
Study on Microstructural Evolution and Strength Growth and Fracture Mechanism of Cemented Paste Backfill
}

\author{
Jian-Xin Fu, ${ }^{1,2}$ Wei-Dong Song, ${ }^{1,2}$ and Yu-Ye Tan ${ }^{1,2}$ \\ ${ }^{1}$ Key Laboratory of the Ministry of Education of China for High-Efficient Mining and Safety of Metal Mines, \\ University of Science and Technology Beijing, Beijing 100083, China \\ ${ }^{2}$ School of Civil and Environmental Engineering, University of Science and Technology Beijing, Beijing 100083, China \\ Correspondence should be addressed to Wei-Dong Song; songwd2004@126.com
}

Received 14 June 2016; Revised 28 July 2016; Accepted 31 July 2016

Academic Editor: Charles C. Sorrell

Copyright (C) 2016 Jian-Xin Fu et al. This is an open access article distributed under the Creative Commons Attribution License, which permits unrestricted use, distribution, and reproduction in any medium, provided the original work is properly cited.

\begin{abstract}
The relations among the uniaxial compressive strength of cemented paste backfill (CPB) with solid phase mass fraction, cement sand ratio, and curing age were studied. The UCS of CPB samples increased exponentially with the increase of solid phase mass fraction and curing age but increased linearly with the increase of cement sand ratio. The results of X-ray diffraction (XRD) and scanning electron microscope (SEM) showed that the strength was determined by the amount of ettringite and C-S-H gelling. With the increase of ettringite and C-S-H gelling, the strength became larger. The triaxial compression test was conducted by selecting four kinds of CPB samples. The results showed that, with the increase of confining pressure, peak and residual strength became larger, but the elastic modulus decreased. When the ratio of confining pressure and uniaxial strength is about $1: 2$, the CPB samples show significant ductility characteristics and the ratio of residual strength and peak strength increased obviously.
\end{abstract}

\section{Introduction}

Filling method is one of the three major mining methods in metal mine [1-3], which uses filling materials to fill mining space in order to support the surrounding rock and control the stability of gob [4-6]. At present, the frequently used backfill materials are cemented paste backfill $(\mathrm{CPB})[1,7]$ which is made by mixed tailings and cement according to a certain proportion and reaches the required strength after a period of time of solidification. The CPB usually plays a role of controlling the deformation of surrounding rock $[8,9]$.

At present, the mixture ratio design of $\mathrm{CPB}$ refers to the relevant theory of concrete. Mitchell and Wong established the strength model by a large quantity of tests which show that the uniaxial compressive strength relates to the porosity, water cement ratio, and binder content [10-13]. Swan used "cementing agent coefficient" to estimate the uniaxial compressive strength which is related to the cementing agent content [14-16]. The most influential filling strength model was Arioglu model [17]. Arioglu established the relationship between the uniaxial compressive strength and water cement ratio and cohesive strength through the study on the properties of coarse aggregate and cemented tailings filling.

However, there was obvious difference between $\mathrm{CPB}$ material and concrete material $[18,19]$. The water cement ratio of mine filling slurry was generally more than 2 , but the new mixed concrete was usually $0.4 \sim 0.6$. The strength of concrete was generally greater than the strength of the filling body several times and even ten times. The strength of the post-peak was different from concrete in the special stress environment after being filled into the stopes, and its residual strength could be stably maintained at a certain value.

Related experiments have shown that the strength of $\mathrm{CPB}$ was closely related to solid mass fraction of tailings slurry, cement sand ratio, and curing age $[20,21]$. Whole tailings of Daye Iron Mine are used to make CPB in this paper. Firstly, the physical and chemical properties of whole tailings were studied, and then strength sensitivity of $\mathrm{CPB}$ was studied including quantitative functional relationship between strength and solid mass fraction of tailings slurry, cement sand ratio, or curing age. The microstructures of $\mathrm{CPB}$ samples were studied using scanning electron microscope 
TABLE 1: Chemical constituent of whole tailings of Daye Iron Mine.

\begin{tabular}{lc}
\hline Constituents & Content $(\%)$ \\
\hline $\mathrm{SiO}_{2}$ & 26.30 \\
$\mathrm{TFe}$ & 20.79 \\
$\mathrm{SFe}$ & 20.02 \\
$\mathrm{CaO}$ & 12.45 \\
$\mathrm{FeO}$ & 10.90 \\
$\mathrm{Al}_{2} \mathrm{O}_{3}$ & 6.07 \\
$\mathrm{MgO}$ & 5.55 \\
$\mathrm{~S}$ & 1.315 \\
$\mathrm{Ag}$ & 0.38 \\
$\mathrm{TiO} 2$ & 0.232 \\
$\mathrm{Cu}$ & 0.228 \\
$\mathrm{MnO}$ & 0.164 \\
$\mathrm{P}$ & 0.15 \\
$\mathrm{Au}$ & \\
$\mathrm{SrO}$ & 0.101 \\
$\mathrm{Zn}$ & 0.046 \\
$\mathrm{~V} 2 \mathrm{O} 5$ & 0.026 \\
$\mathrm{Co}$ & 0.023 \\
$\mathrm{Ni}$ & 0.013 \\
$\mathrm{~Pb}$ & 0.10 \\
$\mathrm{As}$ & 0.006 \\
\hline
\end{tabular}

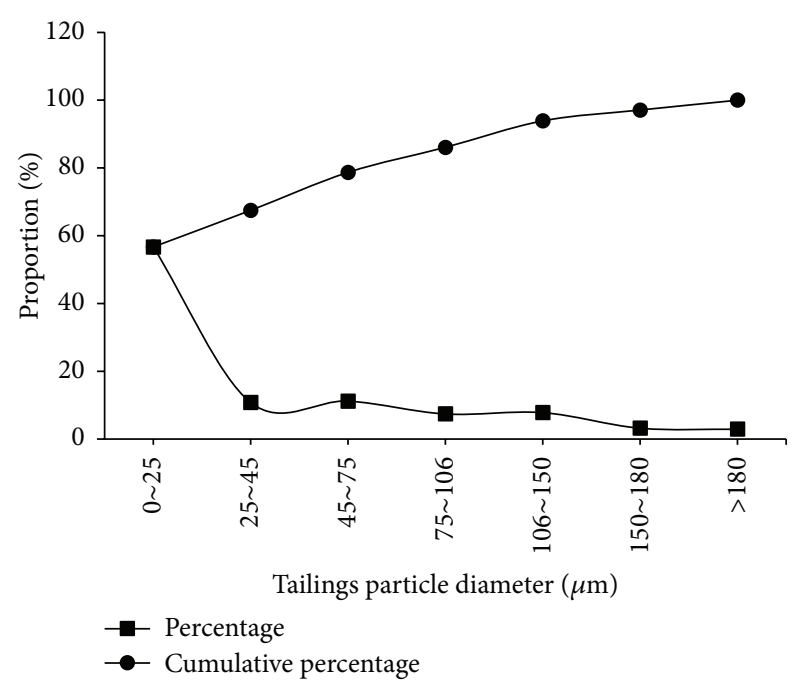

Figure 1: Distribution curves of tailings particle diameter.

(SEM). At last the rupture mechanism of CPB under triaxial stress was studied.

\section{Materials and Methods}

\subsection{Tailings and Binders}

2.1.1. Chemical Constituent of Tailing. The tailings materials used in this study were collected from Daye Iron Mine in Hubei province of China. The chemical analysis method was

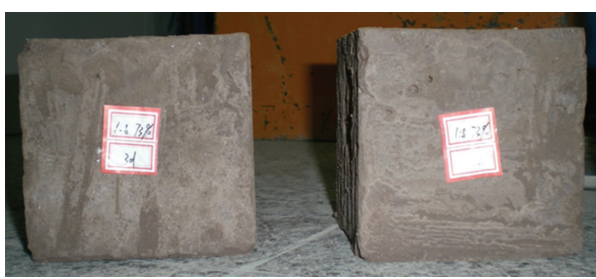

FIgURE 2: CPB samples.

used to study the chemical constituents of the whole backfill, which are shown in Table 1.

It can be seen from the fact that tailings mainly consisted of $\mathrm{SiO}_{2}, \mathrm{CaO}, \mathrm{Al}_{2} \mathrm{O}_{3}$, and so forth. It means that Daye iron ore tailings were mainly composed of clay minerals, quartz, and silicate composition. Secondly, there are $\mathrm{CaO}, \mathrm{MgO}, \mathrm{NaO}$, $\mathrm{SO}_{3}, \mathrm{P}_{2} \mathrm{O}_{5}, \mathrm{Au}, \mathrm{Ag}$, and so on; in addition, they also contain a small amount of $\mathrm{Co}, \mathrm{Ni}, \mathrm{Pb}$, As, and so forth.

2.1.2. Particle Size Distribution. Particle size composition was measured by a laser particle size analyzer. According to the test results, particle size distribution curve of whole tailings was gotten as is shown in Figure 1. The results are shown in Table 2. It is shown that median diameter $\left(d_{50}\right)$ of whole tailings was about $25 \mu \mathrm{m}$.

2.1.3. Physical Properties. The physical properties are the inherent properties of tailings. The test results are shown in Table 3.

2.1.4. Binders. Ordinary Portland cement (OPC, 42.5R) used in this study was obtained from Jidong Cement Plant. The chemical composition and physical characteristics of the OPC were given in Table 4.

2.2. Preparation of $C P B$ Samples. CBP samples were made using Daye Iron Mine whole backfill as aggregate and OPC (42.5R) as binder. The number of samples was 75 . Those samples were divided into five groups taking cement sand ratio as standard, which contained $1: 4,1: 5,1: 6,1: 8$, and $1: 10$. And every group was divided into three parts taking solid phase mass fraction as standard, which contained $65 \%$, $68 \%, 70 \%, 73 \%$, and $75 \%$. Curing age of three samples in each section was 3 days, 7 days, and 28 days.

$\mathrm{CPB}$ samples were made using square mould whose length was $100 \mathrm{~mm}$, and the curing temperature is $(20 \pm 1)^{\circ} \mathrm{C}$, with a relative humidity of more than $90 \%$. The finished samples are shown in Figure 2.

\subsection{UCS and Microstructural Tests}

2.3.1. Uniaxial Compressive Strength Test Method. Following a predetermined period (7, 14, and 28 days) of curing, the CPB samples were tested for unconfined compressive strength (UCS) according to ISO 1920-4-2005 and T0553-2005. The UCS tests were performed using WDW digital display type mechanical testing equipment with a normal load capacity of $50 \mathrm{KN}$ and a displacement speed of $1 \mathrm{~mm} / \mathrm{min}$. All of the 
TABLE 2: Characteristic value of particle size.

\begin{tabular}{lccc}
\hline Fineness/mesh & Particle size/ $\mu \mathrm{m}$ & Percentage/\% & Cumulative percentage/\% \\
\hline$<500$ & $0 \sim 25$ & 56.7 & 56.7 \\
$500 \sim 325$ & $25 \sim 45$ & 10.8 & 67.5 \\
$325 \sim 200$ & $45 \sim 75$ & 11.2 & 78.7 \\
$200 \sim 150$ & $75 \sim 106$ & 7.4 & 86.1 \\
$150 \sim 100$ & $106 \sim 150$ & 7.8 & 93.9 \\
$100 \sim 80$ & $150 \sim 180$ & 3.2 & 97.1 \\
$>80$ & $>180$ & 2.9 & 100 \\
\hline
\end{tabular}

TABLE 3: The list of physical properties of whole tailings.

\begin{tabular}{|c|c|c|c|}
\hline Specific gravity $/ \gamma$ & Bulk density $/ t \cdot \mathrm{m}^{-3}$ & Porosity $\omega / \%$ & Specific surface area $\omega / \mathrm{cm}^{2} \cdot \mathrm{cm}^{-3}$ \\
\hline 1.47 & 3.2 & 57 & 6400 \\
\hline
\end{tabular}

TABLE 4: The list of physical properties of binders.

\begin{tabular}{lcc}
\hline Specific gravity $/ \gamma$ & Bulk density $/ \mathrm{t} \cdot \mathrm{m}^{-3}$ & Porosity $\omega / \%$ \\
\hline 1.3 & 3.10 & 58.06 \\
\hline
\end{tabular}

experiments were carried out in triplicate, and the mean UCS values were presented in the results. All data regarding the test were collected by using a computerised data logging system.

2.3.2. Microstructure Analysis. The phase analysis of samples was carried out by X-ray (diffraction XRD, X-ray) diffraction instrument which is $\mathrm{D} / \mathrm{Max}-\mathrm{RC}$ diffraction instrument produced by the Rigak company of Japan. The scanning range is $10^{\circ} \sim 70^{\circ}$ and scanning speed is $80 \mathrm{r} \cdot \mathrm{min}^{-1}$.

The fractured samples obtained from UCS tests were used in SEM studies. The EVO18 type tungsten filament scanning electron microscope produced by the German Carl Zeiss Company was adopted.

\section{Results and Discussion}

Uniaxial compressive strength mechanics test was conducted for every sample, and the final test results are shown in Table 5. Cement sand ratio, solid phase mass fraction, and curing age were the three major factors affecting UCS of CPB samples. The relationship between the UCS and the three factors was, respectively, studied.

In Daye Iron Mine where open stope mining and subsequent filling method has been used, CPB placed into underground voids provides stability during the mining of the adjacent stopes. According to the rock mechanical properties and the mining requirement, a minimum strength of 2.0 MPa after 28 days is suggested to the UCS criteria. It can be seen from Table 5 that when the cement sand ratio is $1: 4$, all the CPB samples with different solid phase mass fraction meet the requirement. When the cement sand ratio is $1: 5$, the CPB samples with solid phase mass fraction of $68 \%, 70 \%$, $73 \%$, and $75 \%$ meet the requirement. When the cement sand ratio is $1: 6$, the $\mathrm{CPB}$ samples with solid phase mass fraction of $70 \%, 73 \%$, and $75 \%$ meet the requirement. When the cement sand ratio is $1: 8$, the $\mathrm{CPB}$ samples with solid phase mass fraction of $73 \%$ and $75 \%$ meet the requirement. When the cement sand ratio is $1: 8$, all the CPB samples with different solid phase mass fraction do not meet the requirement.

3.1. Effect of Solid Phase Mass Fraction. Taking cement sand ratio as invariant, the change in strength of samples of different curing age with solid phase mass fraction was studied. Besides, the tendency equation is introduced, respectively, by exponential fitting method. The strength histogram of samples of different curing age and exponential fitting curve are shown in Figure 3. Figure 3 points that the UCS of different $\mathrm{CPB}$ samples increase with the increase of the cement sand ratio when the curing age is less than 28 days [22].

The average value of exponential fitting complex correlation coefficient was 0.988 , which means the influence law of solid phase mass fraction on the strength is obvious exponential function. It means that the greater the solid phase mass fraction, the more intense the influence on the strength. The greater the cement sand ratio, the bigger the slope of curves, which means that, with the increase of the cement sand ratio, the influence of solid phase mass fraction on the UCS increases.

It could be seen that the exponential curve of UCS development of CPB samples with different solid phase mass fraction at 3 and 28 days of curing age distributed evenly from down to up, but the distribution of exponential curve at 7 days of curing age is discrete. The exponential curve of the $1: 8$ and $1: 10$ of cement sand ratio at 7 days of curing age is far lower than these of the $1: 4,1: 5$, and $1: 6$ of cement sand ratio.

Above all, the influence of solid phase mass fraction on strength could be expressed as the following formula:

$$
y=a_{1}+b_{1} e^{c_{1} x}
$$

where the values of $a_{1}, b_{1}$, and $c_{1}$ depend on the cement sand ratio and curing age; $x$ is solid phase mass fraction; $y$ is UCS of CPB samples.

3.2. Effect of Cement Sand Ratio. Taking the solid phase mass fraction as invariant, the change in strength of samples of different curing age with cement sand ratio was studied. 
TABLE 5: Uniaxial compression strength of CPB (unit: MPa).

\begin{tabular}{|c|c|c|c|c|c|c|}
\hline \multirow{2}{*}{ Cement sand ratio } & \multirow{2}{*}{ Curing age/d } & \multicolumn{5}{|c|}{ Solid phase mass fraction/\% } \\
\hline & & 65 & 68 & 70 & 73 & 75 \\
\hline \multirow{3}{*}{$1: 4$} & 3 & 0.28 & 0.36 & 0.46 & 0.6 & 0.84 \\
\hline & 7 & 0.81 & 0.96 & 1.39 & 1.61 & 1.96 \\
\hline & 28 & 2.15 & 2.88 & 3.68 & 4.62 & 5.48 \\
\hline \multirow{3}{*}{$1: 5$} & 3 & 0.27 & 0.31 & 0.39 & 0.48 & 0.66 \\
\hline & 7 & 0.72 & 0.81 & 1.34 & 1.58 & 1.91 \\
\hline & 28 & 1.80 & 2.22 & 3.02 & 3.91 & 5.00 \\
\hline \multirow{3}{*}{$1: 6$} & 3 & 0.26 & 0.28 & 0.34 & 0.44 & 0.51 \\
\hline & 7 & 0.69 & 0.80 & 1.30 & 1.53 & 1.89 \\
\hline & 28 & 1.34 & 1.60 & 2.13 & 2.85 & 3.74 \\
\hline \multirow{3}{*}{$1: 8$} & 3 & 0.18 & 0.22 & 0.28 & 0.36 & 0.41 \\
\hline & 7 & 0.31 & 0.39 & 0.56 & 0.66 & 0.70 \\
\hline & 28 & 1.05 & 1.36 & 1.78 & 2.11 & 2.61 \\
\hline \multirow{3}{*}{$1: 10$} & 3 & 0.15 & 0.20 & 0.26 & 0.34 & 0.38 \\
\hline & 7 & 0.24 & 0.36 & 0.44 & 0.58 & 0.63 \\
\hline & 28 & 0.61 & 0.79 & 1.14 & 1.43 & 1.81 \\
\hline
\end{tabular}

Besides, the tendency equation is introduced, respectively, by linear fitting method. The strength histogram of different curing age and linear fitting curve were shown in Figure 4.

The average value of exponential fitting complex correlation coefficient was 0.932 , which means the influence law of cement sand ratio on the strength is obvious linear function. It could be seen from Figure 4 that the greater the cement sand ratio, the more intense the influence on the strength. The highest strength was obtained using the $75 \%$ of solid phase mass fraction and 1:4 of cement sand ratio, which is three times higher than the strength obtained using the $65 \%$ of solid phase mass fraction and 1:10 of cement sand ratio.

Yin et al. [23] investigated the effect of cement content on the mechanical behavior of CPB samples. There is a linear (quasi-linearity) and proportional relationship between the proportions of binder and the obtained mechanical resistance.

Above all, the influence of cement sand ratio on strength could be expressed as the following formula:

$$
y=a_{2}+b_{2} r
$$

where the value of $a_{2}$ and $b_{2}$ depends on the solid phase mass fraction, curing age, and so on; $r$ is cement sand ratio; $y$ is strength of CPB.

3.3. Effect of Curing Age. Taking the CPB samples whose solid phase mass fraction is $68 \%$ and $73 \%$ as the research object, the increasing law of UCS of CPB with different cement sand ratio along with the increase of curing age was studied. The strength histogram of samples and exponential fitting curve were shown in Figure 5. Then, taking the CPB samples whose cement sand ratio is $1: 5$ and $1: 8$ as the research object, the increasing law of UCS of CPB with different solid phase mass along with the increase of curing age was studied. The strength histogram of samples and exponential fitting curve were shown in Figure 6.
It could be seen from Figures 5 and 6 that the average value of exponential fitting complex correlation coefficients is more than 0.9 which means the influence law of curing age on the UCS is obvious exponential function, and the greater the cement sand ratio, the greater the slope of curves.

Above all, the influence of curing age on strength could be expressed as the following formula:

$$
y=a_{3}+b_{3} e^{c_{3} t}
$$

where the value of $a_{2}$ and $b_{2}$ depends on the solid phase mass fraction, cement sand ratio, and so forth; $t$ is curing age; $y$ is strength of CPB.

3.4. The Degree of Influence. The above analysis shows that UCS of CPB samples had ties with cement sand ratio, solid phase mass fraction, and curing age but the influence susceptibility was different. Taking five kinds of CPB samples with different cement sand ratio and solid phase mass fraction as research object, the strength data in Table 1 with different curing age were shown in Figure 7.

From the above analysis it can be observed that, with the increase of cement sand ratio, solid phase mass fraction, and curing age, the UCS increases in various ways. However, it could be seen from Figure 7 that when curing age is 3 days, UCS of CPB samples gradually increases with increase of solid phase mass fraction, but with decrease of cement sand ratio, which means that the solid phase mass fraction had greater effect on the UCS. From Figure 7 it can also be observed that the UCS of CPB samples at 7 and 28 days of curing age increases first and then reduces with increasing of solid phase mass fraction and decreasing of cement sand ratio. The maximum UCS of CPB samples at 7 and 28 days are separately $1.3 \mathrm{MPa}$ and $2.22 \mathrm{MPa}$, which separately occur at the $1: 6$ of cement sand ratio, $70 \%$ of solid phase mass fraction, and 1:5 of cement sand ratio, $68 \%$ of solid phase mass fraction. After that, the UCS of CPB samples decreases 

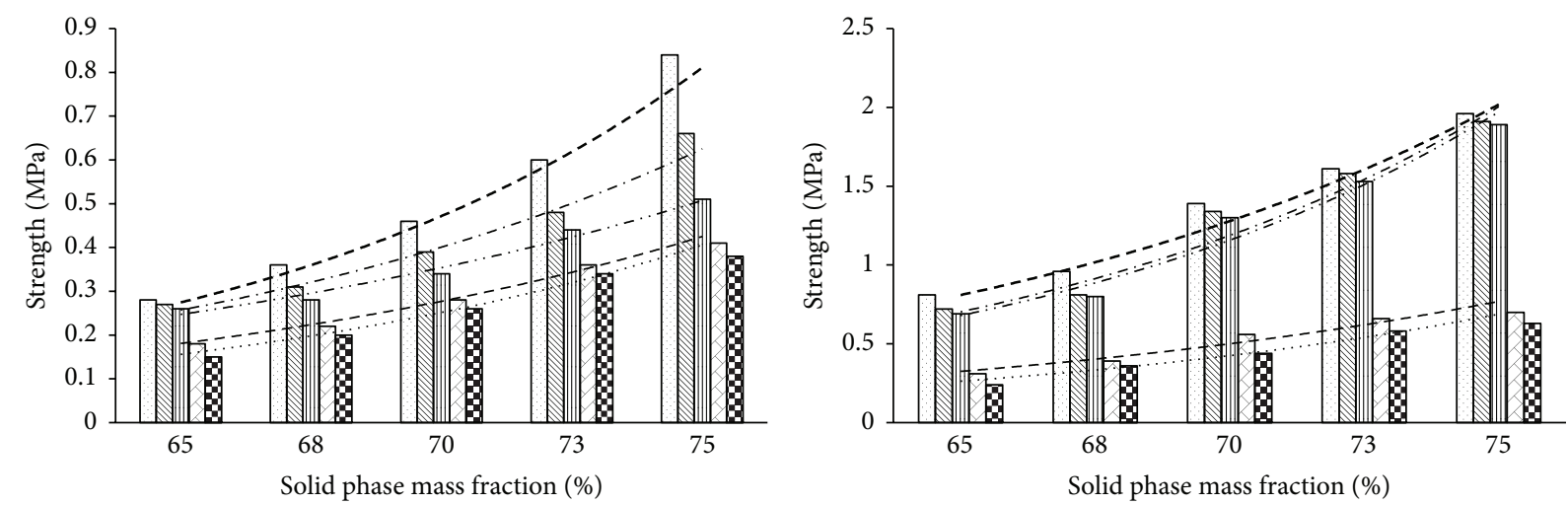

\begin{tabular}{|c|c|c|}
\hline- & Cement & $---1: 4$ \\
\hline 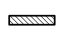 & Cement sand ratio $1: 5$ & $1: 5$ \\
\hline & Cem & \\
\hline & Cer & \\
\hline & Cement sand ratio $1: 10$ & \\
\hline
\end{tabular}

(a)

$\begin{array}{lll}\text { Cement sand ratio } 1: 4 & ---1: 4 \\ \text { Cement sand ratio } 1: 5 & -- & 1: 5 \\ \text { Cement sand ratio } 1: 6 & -\cdots & 1: 6 \\ \text { Cement sand ratio } 1: 8 & --- & 1: 8 \\ \text { Cement sand ratio } 1: 10 & \cdots \cdots & 1: 10\end{array}$

(b)

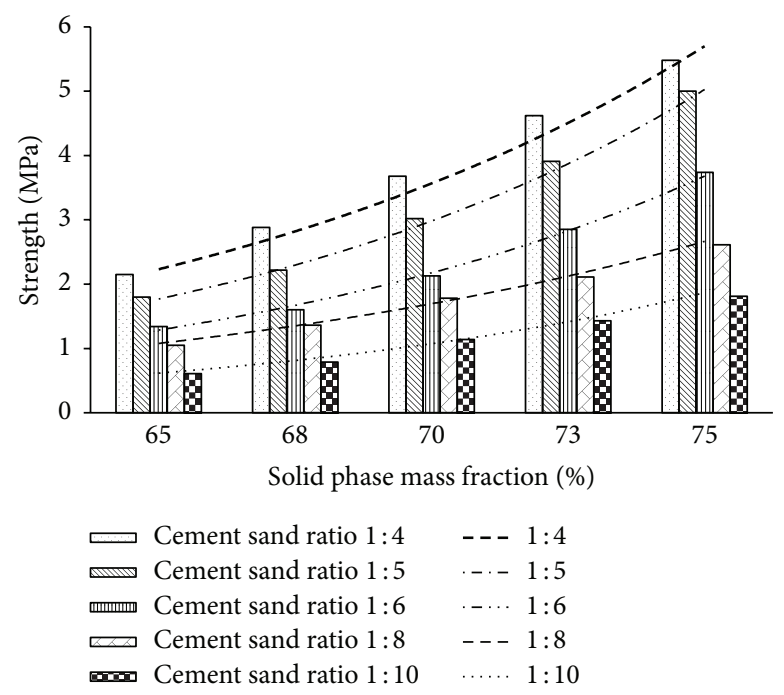

(c)

Figure 3: Relationships of solid phase mass fraction and the strength. (a) Curing age was 3 days; (b) curing age was 7 days; (c) curing age was 28 days.

with increasing of solid phase mass fraction and decreasing of cement sand ratio. The above experimental phenomena show that the cement sand ratio has a greater impact on the UCS before the maximum UCS. After the maximum UCS, the solid phase mass fraction has a greater impact on the UCS. The influence degree of solid phase mass fraction weakens along with the increasing of curing age.

In addition, from Table 5 it can be observed that the UCS of CPB samples with 1:5 of cement sand ratio at the 7 days of curing age separately increases by $15.9 \%$; $94.2 \%$; $127.5 \% ; 179.7 \%$. The UCS of CPB samples with 1:5 of cement sand ratio and $65 \%$ of solid phase mass fraction separately increase by $166.7 \%$ and $566.7 \%$. When the solid phase mass fraction is $70 \%$ the UCS of CPB samples at 3 days of curing age separately increases by $7.69 \%, 23.1 \%, 50 \%$, and $76.9 \%$. The above analysis shows that the curing age has the greatest impact on the UCS of CPB samples.
3.5. Microstructural Evolution of CPB Samples. The phases of CPB samples of different curing age were analyzed using $\mathrm{X}$-ray diffraction (XRD). The results are shown in Figure 8 which is the diffraction pattern of CPB samples at 3 days, 7 days, and 28 days of curing age. The distribution of hydration products in different curing age was the form of "needle peak" which shows a large number of low crystallinity and noncrystalline materials generated. It can be seen that there are a lot of ettringite, calcium silicate hydrate (C-S-H), and calcium hydroxide, but only a small amount of complex salt hydrates after 3 days. The ettringite is high crystalline mineral which was generated by reacting of calcium aluminate hydrate and gypsum. The ettringite could rapidly absorb free water and play an active role on early strength of CPB samples. With the continuing of hydration reaction, gels of hydrated calcium aluminate and calcium hydroxide continued to increase and crystallize, then combined with calcium silicate hydrate, and 

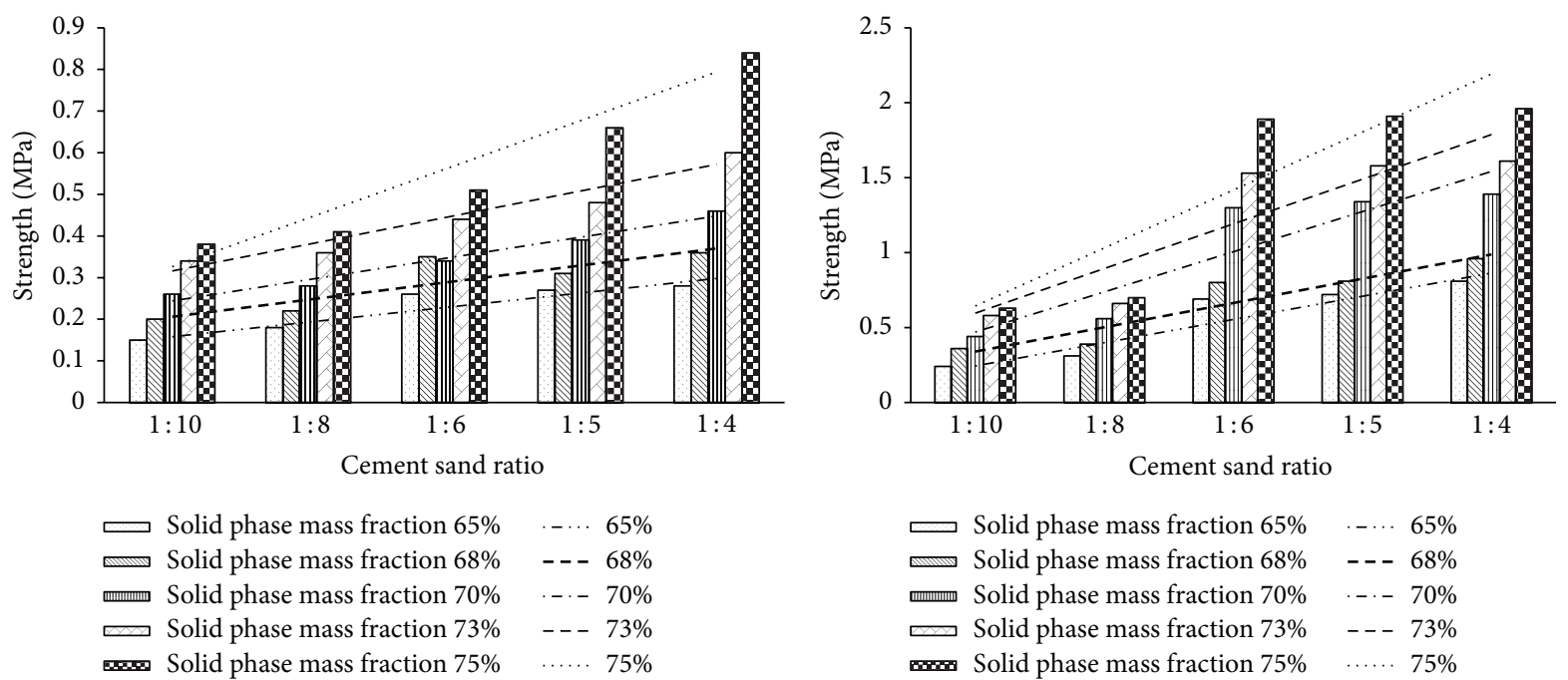

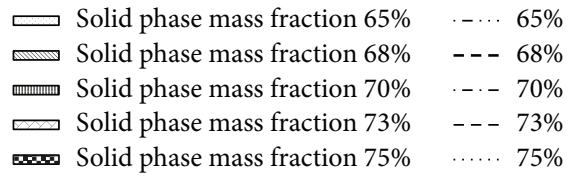

(a)

(b)

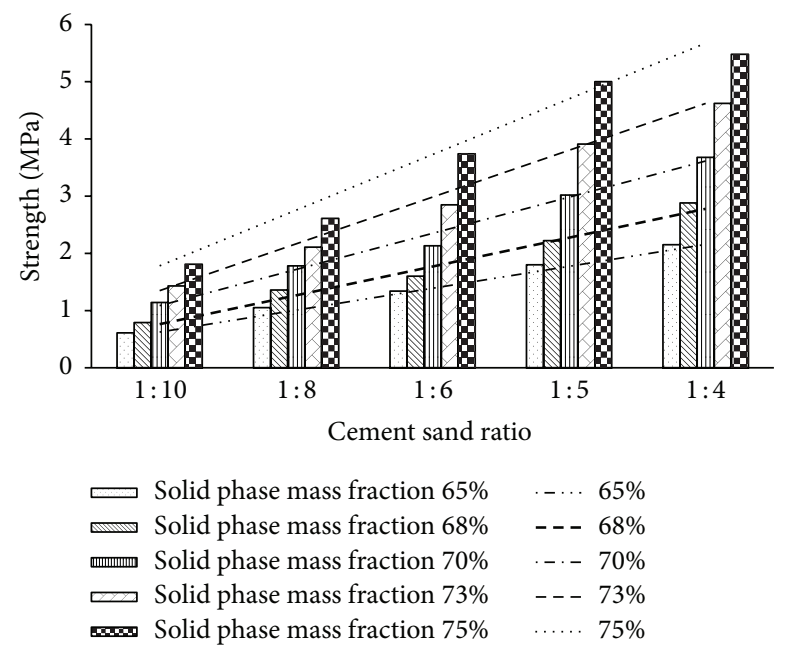

(c)

FIGURE 4: Relationships of cement sand ratio and the strength. (a) Curing age was 3 days; (b) curing age was 7 days; (c) curing age was 28 days.
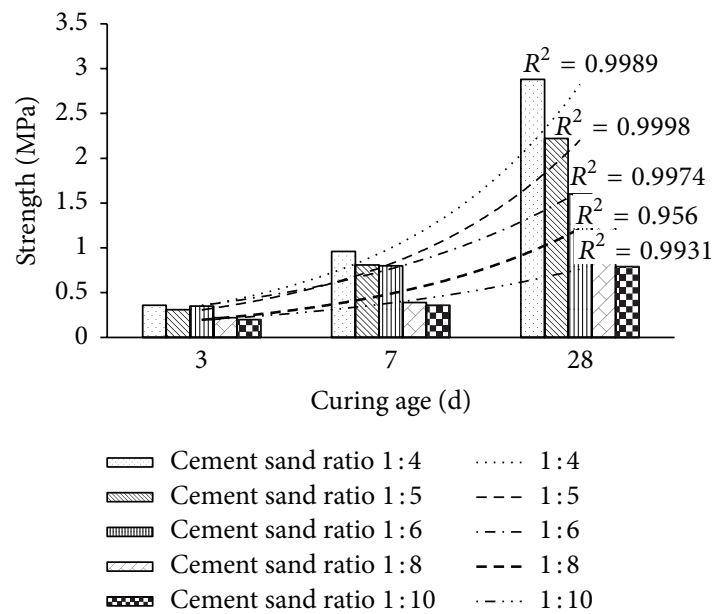

(a)
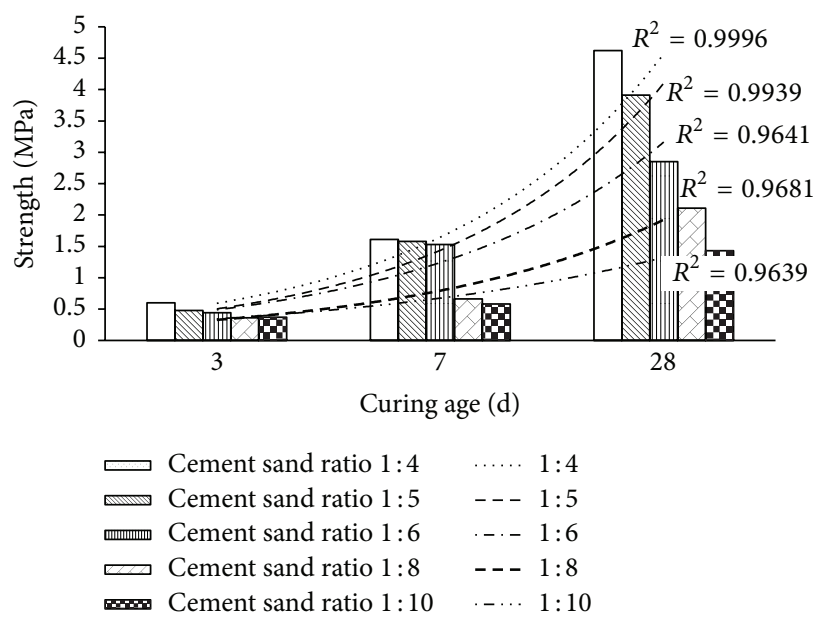

(b)

FIGURE 5: Relationships of curing age and the strength. (a) Solid phase mass fraction was 68\%; (b) solid phase mass fraction was $73 \%$. 

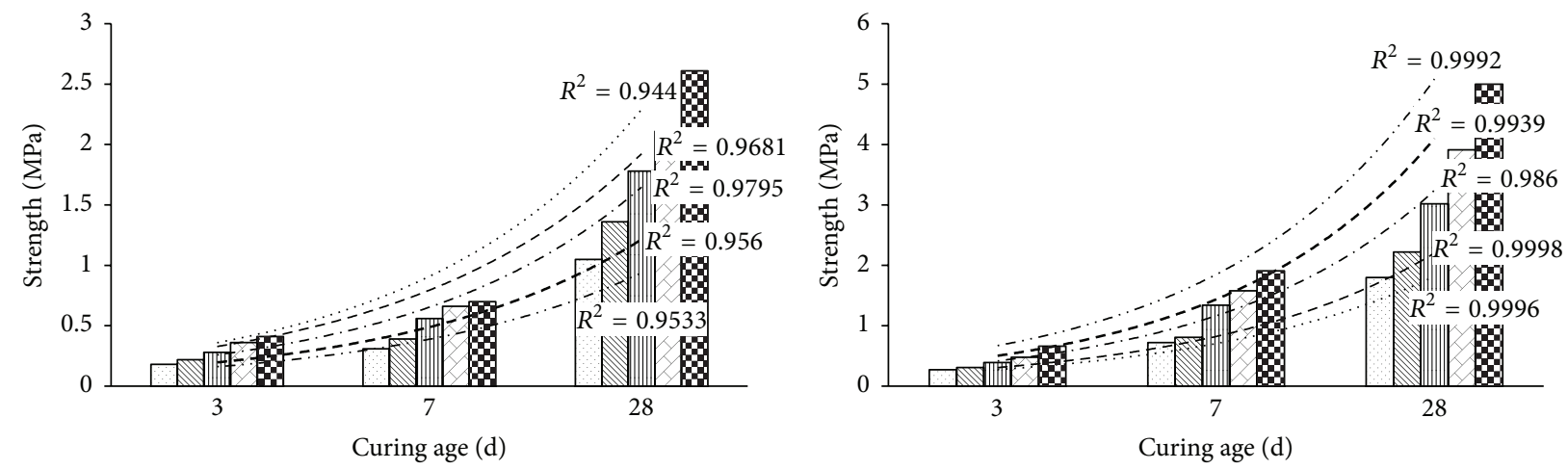

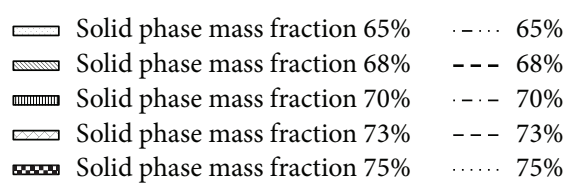

(a)

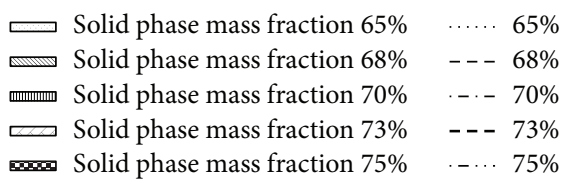

(b)

Figure 6: Relationships of curing age and the strength. (a) Cement sand ratio was 1:8; (b) cement sand ratio was 1:5.

promoted the growth of strength of CPB samples. So the $\mathrm{C}-\mathrm{S}-\mathrm{H}$ played a key role on the strength development of
$\mathrm{CPB}$ samples. The major hydration reaction of C-S-H can be expressed as [24]

$$
3 \mathrm{CaO} \cdot \mathrm{SiO}_{2}+2 \mathrm{CaO} \cdot \mathrm{SiO}_{2}+\mathrm{H}_{2} \mathrm{O} \longrightarrow 2 \mathrm{CaO} \cdot \mathrm{SiO}_{2} \cdot n \mathrm{H}_{2} \mathrm{O}+\mathrm{Ca}(\mathrm{OH})_{2}
$$

It has been reported that [25] C-S-H is generally accepted as being the major load-bearing phase in cement paste; it is evident that increasing the C-S-H content in the cement matrix will lead to a higher bond strength between tailings particles and the cement matrix and consequently to a higher $\mathrm{CPB}$ strength.

It can be seen from Figure 8 that the amount of ettringite and $\mathrm{C}-\mathrm{S}-\mathrm{H}$ grows with the increase of curing age.

The SEM images of CPB samples of different conditions are shown in Figure 9. It is generally known that the strength of $\mathrm{CPB}$ samples is closely related to the microstructure and components. From the above analysis we can know that CHS, gypsum, ettringite, and so forth have important effect on the strength development [26], and the porosity is also an important factor which is related to cement sand ratio and curing age.

From Figures 9(a) and 9(b), it could be seen that the microstructures of $\mathrm{CPB}$ samples at 7 days of curing age with various cement sand ratio are very different. After 7 days of curing, there are a lot of group floc-like C-S-H and aciculate ettringite. By comparing Figures 9 (a) and 9 (b), it can be found that the aciculate ettringite in Figure 9(a) is more than that in Figure 9(b). In addition, the pore in Figure 9(a) is less than Figure 9(b). Based on the above analysis and previous studies, the strength of CPB samples with 1:4 of cement sand ratio is greater than that of $\mathrm{CPB}$ samples with 1:6 cement sand ratio. As shown in Figures 9(a) and 9(d), it can be observed that the group floc-like C-S-H in Figure 9(d) is more than that in
Figure 9(a), which means that the cement hydration degree of $65 \%$ of solid phase mass fraction is much severer than that of $70 \%$ of solid phase mass fraction.

The SEM images of CPB samples with $70 \%$ of solid phase mass fraction at $1: 4$ of cement sand ratio at 3 days, 7 days, 28 days, and 56 days of curing age are shown in Figures 9(c)-9(f). It can be seen that there are many needles with dense structure which are linked by $\mathrm{C}-\mathrm{S}-\mathrm{H}$ gelling after 3 days (Figure 9(c)). With the growth of curing age, a lot of C-S-H gelling is generated after 7 days which makes bond strength of hydration products greater and improves the mechanical strength and durability. In addition, there are a few needles, most parts of which are covered by C-S-H gelling. After 28 days (Figure $9(\mathrm{e})$ ), the bond strength of C-S-H gelling becomes greater, most of which exists as overall form. It means that the hydration reaction degree and crystallinity of hydration products significantly increase, which causes the strength to become greater. After 56 days (Figure 9(f)), there were almost no needles generated in the early period of hydration reaction; most of the hydration products exist as lump or block form and closely bond to each other. In addition, the porosity decreases with the increase of curing age, depending on the cement sand ratio and solid phase mass fraction.

Based on the analysis, the microstructure and components are closely related to the curing age, cement sand ratio, and solid phase mass fraction. The factors affecting the strength development mainly include the C-S-H, ettringite, 


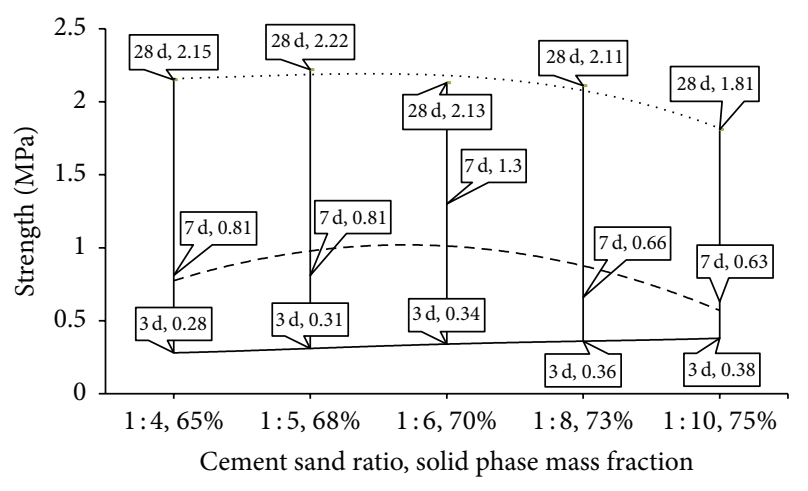

FIGURE 7: Distribution of strength of different CPB samples.

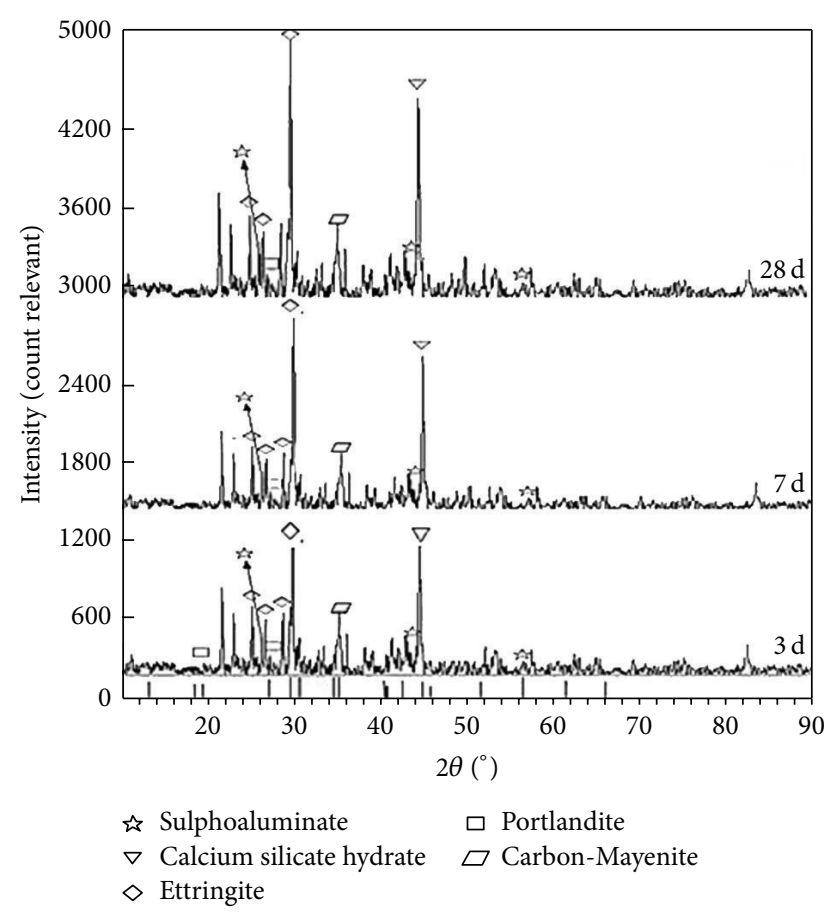

FIGURE 8: XRD diffraction of hydration products.

and porosity. Increasing the binder dosage apparently improved the microstructure of the SPB samples with the formation of additional C-S-H gelling [27, 28]. Additionally, as the cement sand ratio decreases or curing age increases, total porosity is reduced, mainly due to the reduction in larger-sized pores by partial filling with cementitious phases [23].

When the curing age is 56 days the secondary gypsum was clearly detected, which was claimed to be responsible for the reduction of strength of CPB samples after 56 and 90 days, respectively, due to its expansive properties [22, 28, 29].

3.6. Failure Mechanism of CPB Samples under Triaxial Stress. In fact, the $\mathrm{CPB}$ was under triaxial stress conditions after being filled into the stopes. It was significantly important to know well the mechanical behavior of cemented paste backfill under triaxial stress.
TABLE 6: List of cohesion and internal friction angles.

\begin{tabular}{lcccc}
\hline & \multicolumn{2}{c}{$1: 6$} & \multicolumn{2}{c}{$1: 8$} \\
& $65 \%$ & $70 \%$ & $65 \%$ & $70 \%$ \\
\hline Cohesion/MPa & 1.012 & 1.361 & 0.779 & 1.156 \\
Internal friction angle $(\varphi) /^{\circ}$ & $34^{\circ}$ & $31^{\circ}$ & $37^{\circ}$ & $36^{\circ}$ \\
\hline
\end{tabular}

The CPB samples were tested for confined compression strength according to ASTM C 39. The solid phase mass fraction and cement sand ratio of selected samples were as follows: (1) Type 1: cement sand ratio was $1: 6$, and solid phase mass fraction was $65 \%$; (2) Type 2: cement sand ratio was $1: 6$, and solid phase mass fraction was 70\%; (3) Type 3: cement sand ratio was $1: 8$, and solid phase mass fraction was $65 \%$; (4) Type 4: cement sand ratio was 1:6, and solid phase mass fraction was $70 \%$. The samples were conserved in isothermal curing box for 28 days. These samples are shown in Figure 10.

The loading mode was axial displacement control and the rate was $1 \times 10^{-4} \mathrm{~mm} / \mathrm{s}$. The confining pressures include 0.4 MPa, 0.6 MPa, 0.8 $\mathrm{MPa}$, and 1.0 MPa. Mohr's circles are shown in Figure 11.

The cohesion $(c)$ and internal friction angle $(\varphi)$ are shown in Table 6. It could be seen that when the solid phase mass fraction is constant, the cement sand ratio, the cohesion $(c)$, and internal friction angle are greater. When the cement sand ratio is constant, the solid phase mass fraction and the cohesion $(c)$ are greater, while the internal friction angle is smaller.

3.6.1. Analysis on Complete Stress: Strain Curves of $C P B$ Samples. The test data are shown in Table 7. The contents in the row of serial number represented the type of CPB samples (i.e., the "1-" " represented Type 1, the "2-" " represented Type 2 , the " $3-^{*}$ " represented Type 3 , and the " $4-^{*}$ " represented Type 4). The complete stress-strain curves of CPB samples under different confining pressure are shown in Figure 12. It could be seen from Figure 12 that the complete stress-strain curves could be divided into four stages including elastic stage (marked as OB in Figure 12(a), nonlinear failure stage (BC), strain softening stage (CD), and plastic flow stage (DE). The value of point $C$ is the peak strength. The curve can be divided into 2 parts taking point $\mathrm{B}$ as the boundary including elastic segment and plastic.

Elastic stage $(\mathrm{OB})$ of complete stress-strain curve can be expressed as straight line, which is divided into two parts containing initial compaction stage (OA) and the liner elastic stage $(A B)$. There is a very significant initial compaction stage which means that $\mathrm{CPB}$ samples largely deformed under little stress. It is because CPB is artificial materials in which there are many void defects. The deformation law is very complex in this stage. Linear elastic stage $(\mathrm{AB})$ is the stage of strength formation of $\mathrm{CPB}$ samples. The internal pores have been completely closed resulting in stress-strain curves of this stage being straight lines. The deformation characteristics of CPB samples could be described by elastic modulus $(E)$ and Poisson ratio $(\mu)$ referring to rock mechanics. Indeed, as confining pressure increases, the elastic modulus increases. 


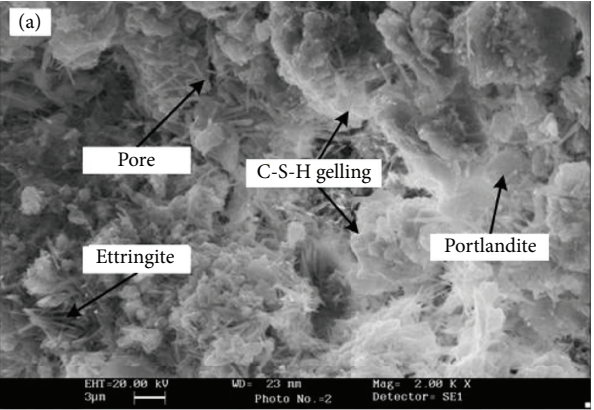

$1: 4,65 \%, 7 \mathrm{~d}$

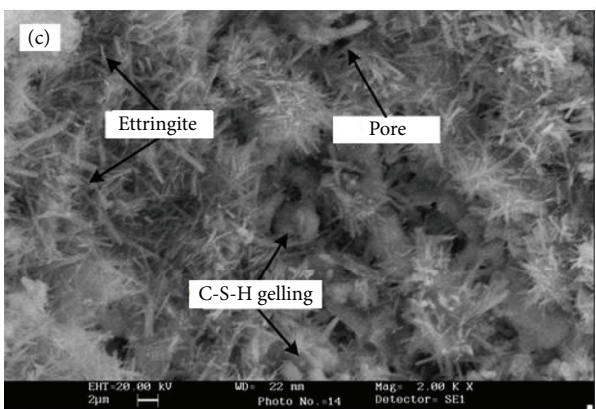

$1: 4,70 \%, 3 \mathrm{~d}$

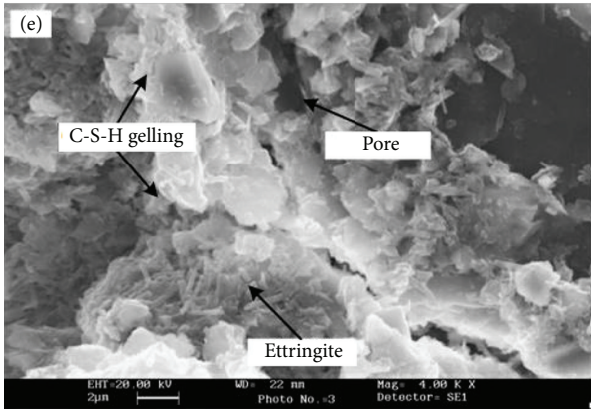

$1: 4,70 \%, 28 \mathrm{~d}$

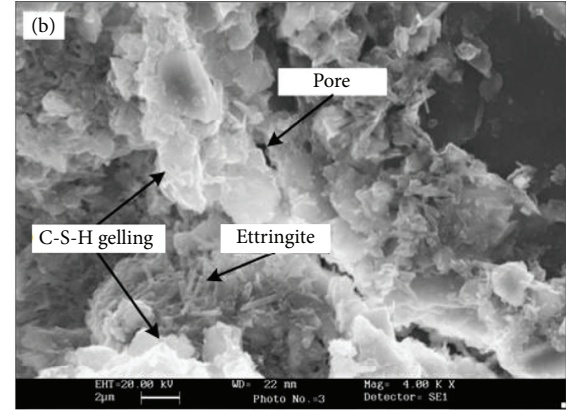

$1: 6,65 \%, 7 \mathrm{~d}$

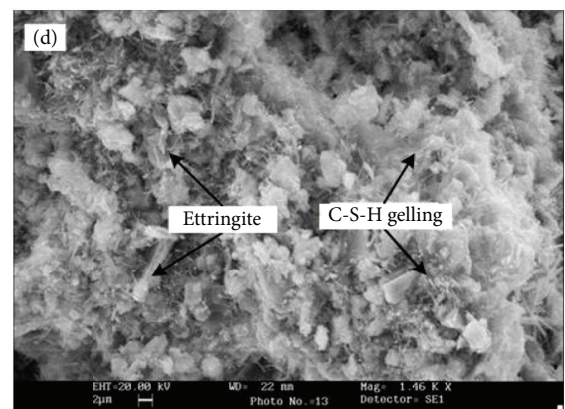

$1: 4,70 \%, 7 \mathrm{~d}$

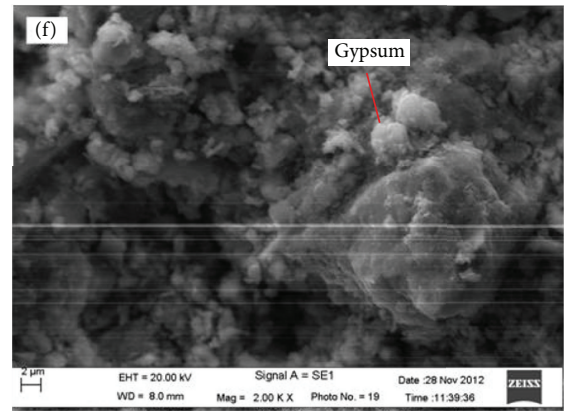

$1: 4,70 \%, 56 \mathrm{~d}$

FiguRE 9: SEM images of CPB samples of different condition.

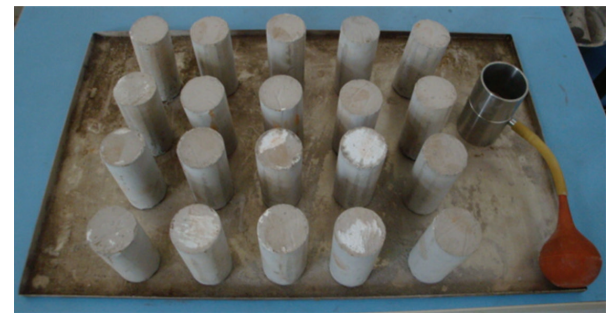

FIgURE 10: Samples of triaxial compression test.

Nonlinear failure stage (BC) is the stage of generating, development, and accumulating of micro cracks in $\mathrm{CPB}$ samples. When the internal cracks link up with each other, yield surface begins to form. With the development of yield surface, CPB samples reach the ultimate bearing capacity. The greater the confining pressure, the longer the stage, and the greater the peak strength. Then the CPB samples enter strain softening stage (CD). With increase of strain, the stress gradually decreases after peak strength and CPB samples show progressive failure and fracture surface gradually forms. After point $\mathrm{D}$, the stress has no significant change. After that, $\mathrm{CPB}$ samples enter into plastic flow stage where the stress no longer reduces with increase of strain.

For the same type of samples, with the increase of confining pressure, peak point becomes not noticeable. When the confining pressure was less than or equal to $0.6 \mathrm{MPa}$, with the increase of strain, the stress became significantly smaller in the strain softening stage $(\mathrm{CD})$. When the confining pressure is more than $0.6 \mathrm{MPa}$, there are no clear boundaries between nonlinear failure stage and strain softening stage. The average ratios of residual strength and peak strength under different confining pressure are $72.56 \%, 86.72 \%, 90.06 \%$, and $94.13 \%$. The solid phase mass fraction has significant effect on the three-dimensional mechanical properties of CPB samples. 


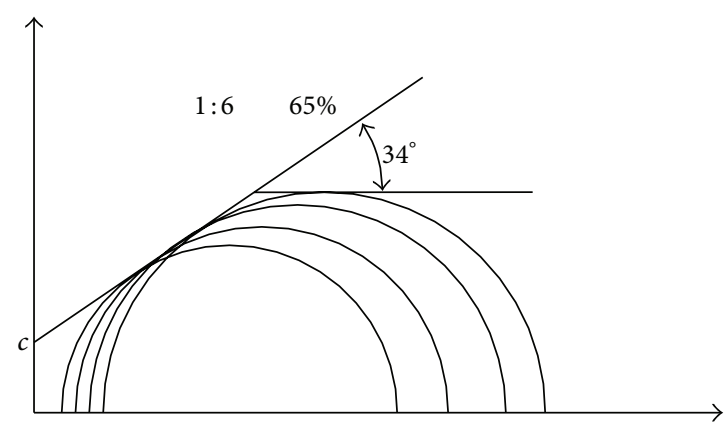

(a)

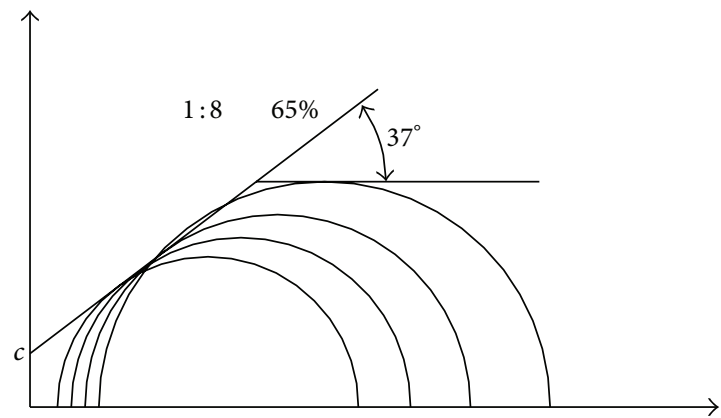

(c)

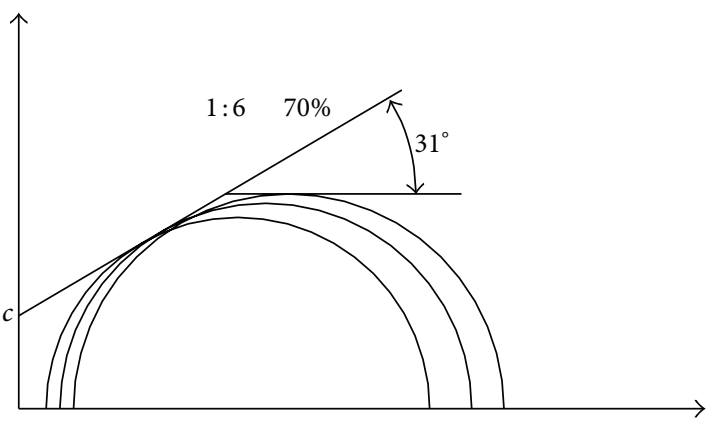

(b)

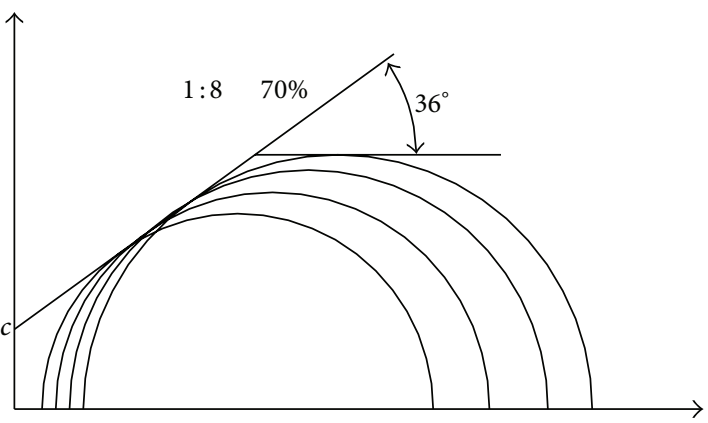

(d)

FIGURE 11: Mohr stress circle of different CPB samples.

TABLE 7: Experimental data list.

The ratio of number Confining pressure/MPa Peak load/MPa Residual load/MPa Peak strength/MPa Residual strength/MPa residual and peak

\begin{tabular}{|c|c|c|c|c|c|c|}
\hline & & & & & & strength/\% \\
\hline $1-1$ & 0.4 & 6.11 & 5.12 & 5.25 & 4.40 & 83.80 \\
\hline $1-2$ & 0.6 & 7.34 & 6.64 & 5.94 & 5.11 & 90.46 \\
\hline $1-3$ & 0.8 & 8.48 & 7.75 & 6.82 & 6.23 & 91.39 \\
\hline $1-4$ & 1.0 & 9.19 & 9.01 & 7.39 & 7.39 & 91.95 \\
\hline $2-1$ & 0.4 & 7.80 & 6.39 & 5.99 & 4.91 & 81.92 \\
\hline $2-2$ & 0.6 & 8.18 & 6.67 & 6.61 & 5.55 & 83.99 \\
\hline $2-3$ & 0.8 & 9.19 & 8.16 & 7.12 & 6.27 & 92.83 \\
\hline $2-4$ & 1.0 & 10.53 & 9.98 & 9.07 & 8.60 & 94.81 \\
\hline $3-1$ & 0.4 & 5.32 & 4.51 & 4.76 & 3.88 & 84.77 \\
\hline $3-2$ & 0.6 & 6.33 & 5.50 & 5.52 & 4.93 & 86.89 \\
\hline $3-3$ & 0.8 & 7.44 & 6.38 & 6.39 & 5.51 & 85.75 \\
\hline $3-4$ & 1.0 & 8.65 & 8.51 & 7.55 & 7.39 & 98.38 \\
\hline $4-1$ & 0.4 & 7.06 & 4.84 & 6.06 & 4.34 & 68.56 \\
\hline $4-2$ & 0.6 & 7.26 & 6.21 & 6.28 & 5.42 & 85.54 \\
\hline $4-3$ & 0.8 & 8.33 & 7.52 & 7.19 & 6.46 & 90.28 \\
\hline $4-4$ & 1.0 & 9.64 & 8.81 & 8.37 & 7.69 & 91.39 \\
\hline
\end{tabular}

The greater the solid phase mass fraction is, the more intense the strength decreased after peak strength under the same confining pressure.

3.6.2. Space Failure Characteristics of CPB Samples. It could be seen from above analysis that samples deformation shows significant brittle features and strain softening phenomenon is obvious after peak strength. Stress-strain curve shows the ideal elastic-plastic characteristics. The destruction form is conjugate shear failure. The failure surface is rough and sample appeared as obviously drum-shaped. As shown in Figure 13(a), with the increase of confining pressure, there 


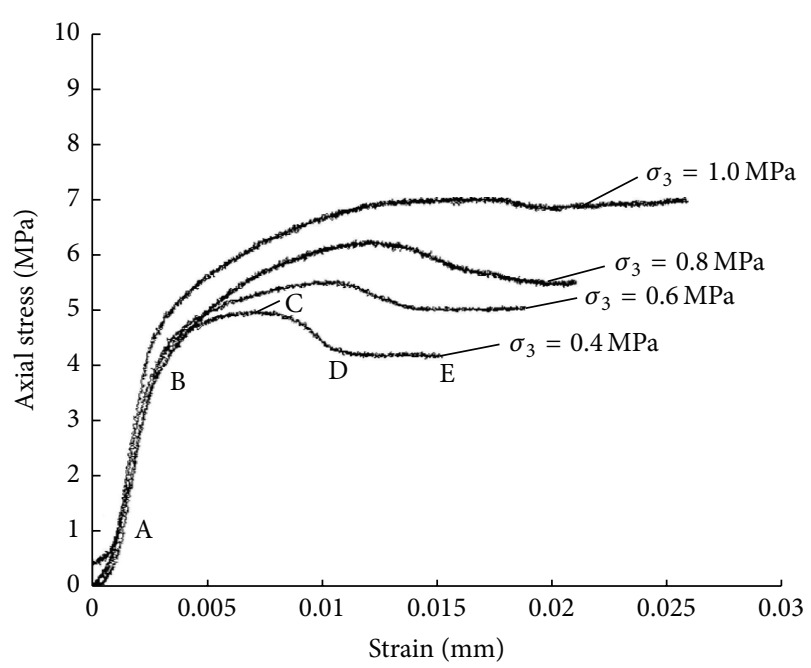

(a) $1: 6,65 \%$

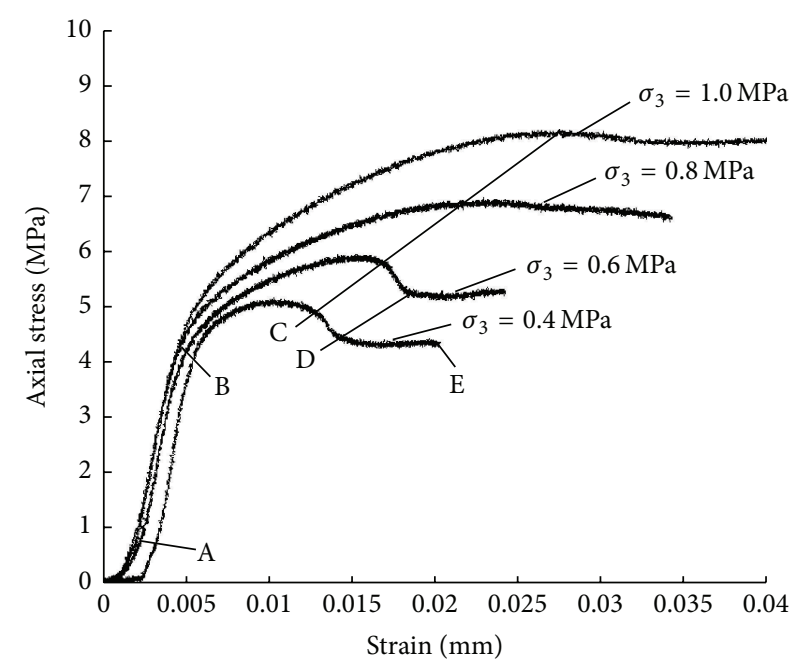

(c) $1: 8,65 \%$

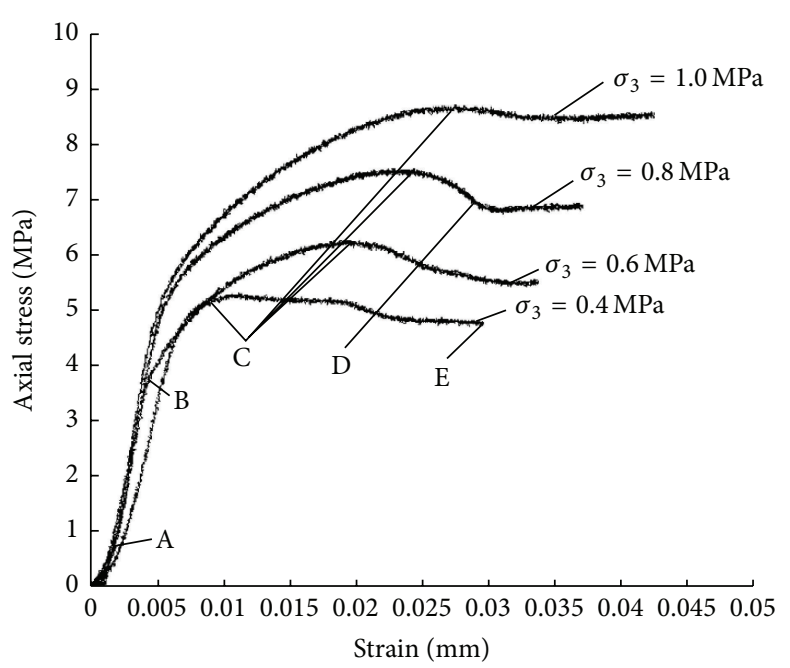

(b) $1: 6,70 \%$

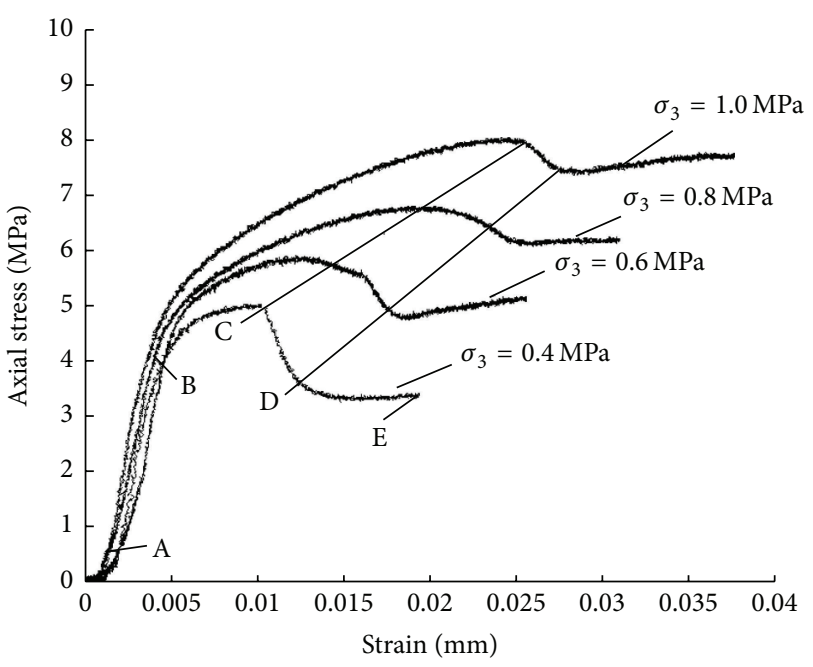

(d) $1: 8,70 \%$

FIgURE 12: Complete stress-strain curves.

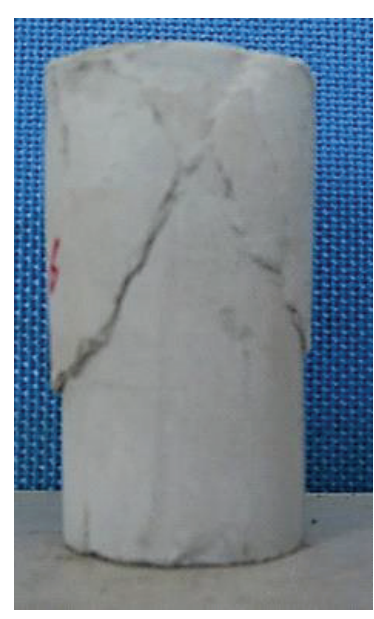

(a)

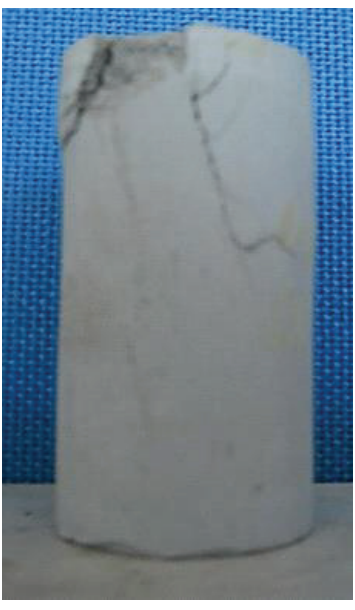

(b)

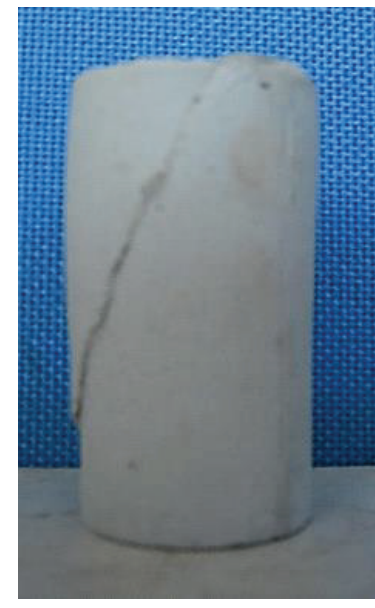

(c)

FIGURE 13: Failure characteristics of CPB samples. (a) Conjugate shear; (b) transitional shear failure; (c) single shear failure. 
is obvious plastic platform on the stress-strain curve before peak strength and the greater the confining pressure, the larger the width of the platform. There is no significant strain softening stage and the rock deformation directly entered into the plastic flow state. The destruction form transits from conjugate shear failure to shear failure which appears as smooth shear plane accompanied by partial crack. CPB samples deformation shows significant ductility features. At this point the ratio of confining pressure and uniaxial strength is about $1: 2$. When confining pressure is $1 \mathrm{MPa}$, the destruction form shows significant single shear failure and the angle of shearing surface is $68^{\circ}$ and the relationship between the angle and the internal friction angle can be expressed as

$$
\beta=\frac{\pi}{4}+\frac{\varphi}{2}
$$

where $\beta$ is representative of angle of shearing surface.

\section{Conclusions}

In this study, the effects of solid phase mass fraction, curing age, and cement sand ratio on the unconfined compressive strength (UCS) of cemented tailings backfill at 3, 7 , and 28 days of curing age were investigated. Additionally, the microstructure and failure mechanism under triaxial compression of backfill were also investigated. Based on the obtained results, the following conclusions can be drawn:

(1) Test results show that there is a definite functional relationship between the strength of CPB samples and solid phase mass fraction, cement sand ratio, and curing age.

(2) The effects of solid phase mass fraction, curing age, and cement sand ratio on the development of UCS of cemented tailings backfill were different. When the other two factors were kept constant, the UCS of CPB samples increased exponentially with the increase of solid phase mass fraction, increased linearly with the increase of cement sand ratio, and increased exponentially with the increase of curing age.

(3) The effect of curing age had the greatest impact on the UCS of CPB samples. With the increase of curing age, the degree of influence of solid phase mass fraction gradually weakened and the degree of influence of cement sand ratio gradually became larger.

(4) The state and type of hydrate were quite different in each curing age. The amount of ettringite and C-S-H gel materials gradually increased. Hydrates gradually bonded together which caused the increase of strength.

(5) The deformation of CPB samples was composed of initial compaction deformation, elastic deformation of the matrix, and inelastic deformation caused by crack propagation. Accumulation of elastic deformation and local stress concentration caused further damage of CPB samples. Damage would lead to anisotropic material and the evolution of damage led to fracture failure.
(6) Confining pressure had obvious impact on the mechanical properties. With the increase of confining pressure, peak strength, peak strain, and the residual strength became larger, but the elastic modulus decreased. So CPB closely contacted with the surrounding rock only can achieve the best effect.

\section{Competing Interests}

The authors declare that they have no competing interests.

\section{Acknowledgments}

Financial supports for this work, provided by the National Natural Science Foundation of China (no. 5137403) and the Fundamental Research Funds for the Central Universities (no. FRF-TP-15-042A1), are gratefully acknowledged. Finally, the first author would like to thank colleagues at USTB for their support.

\section{References}

[1] M. Benzaazoua, M. Fall, and T. Belem, "A contribution to understanding the hardening process of cemented pastefill," Minerals Engineering, vol. 17, no. 2, pp. 141-152, 2004.

[2] E. De Souza, D. De Gagné, and J. F. Archibald, "Mine fill applications, practices and trends in Canadian mines," in Proceedings of the 7th International Symposium on Mining with Backfill, pp. 311-319, Society for Mining, Metallurgy, and Exploration, Seattle, Wash, USA, September 2001.

[3] M. Benzaazoua, D. Bois, T. Belem et al., "St-Onge, Remblais souterrains, évolution des connaissances et de la pratique," in Proceedings of the 20th Colloque Contrôle de Terrains, p. 23, Association Minière du Québec, 2005.

[4] A. Grice, "Underground mining with backfill," in Proceedings of the 2nd Annual Summit, p. 6, Mine Tailings Disposal Systems, Brisbane, Australia, 1998.

[5] A. B. Annor, A study of the characteristics and behaviour of composite backfill material [Ph.D. thesis], McGill University, Montreal, Canada, 1999.

[6] M. Benzaazoua, J. Quellet, S. Servant, P. Newman, and R. Verburg, "Cementitious backfill with high sulfur content: physical, chemical and mineralogical characterization," Cement and Concrete Research, vol. 29, no. 5, pp. 719-725, 1999.

[7] M. Fall, M. Benzaazoua, and S. Ouellet, "Experimental characterization of the influence of tailings fineness and density on the quality of cemented paste backfill," Minerals Engineering, vol. 18, no. 1, pp. 41-44, 2005.

[8] W. D. Song, H. F. Li, Y. K. Lei, and L. F. Mei, "Experimental research on the performance of cemented whole-tailings filling material in Chengchao iron mine," Mining Research and Development, vol. 32, p. 8, 2012.

[9] S. M. F. Asmus, Y. Jianying, and J. S. Almas, "State of the art admixtures for high performance SCC in China," in Proceedings of the 1st International Symposium on Design, Performance and Use of Self-Consolidating Concrete, Changsha, China, May 2005.

[10] K. Senthamarai Kannan, L. Andal, and M. Shanmugasundaram, "An investigation on strength development of cement with cenosphere and silica fume as pozzolanic replacement," Advances in Materials Science and Engineering, vol. 2016, Article ID 9367619, 5 pages, 2016. 
[11] A. Kesimal, B. Ercikdi, and E. Yilmaz, "The effect of desliming by sedimentation on paste backfill performance," Minerals Engineering, vol. 16, no. 10, pp. 1009-1011, 2003.

[12] C. G. Verkerk and R. D. Marcus, "The pumping characteristics and rheology of paste fills," Backfill in South African Mines, vol. 1988, pp. 221-233, 1988.

[13] F. J. Archibald, "Ground waste glass as a pozzolanic consolidation agent for mine backfill," CIM Bulletin, vol. 88, pp. 80-87, 1995.

[14] C. L. Hwang, S. L. Lee, F. Y. Lin, and J. C. Liu, "Densified mix design algorithm and early properties of HPC," Journal of the Chinese Institute of Civil and Hydraulic Engineering, vol. 8, 1994.

[15] A. B. Rodd, D. E. Dunstan, and D. V. Boger, "Characterisation of xanthan gum solutions using dynamic light scattering and rheology," Carbohydrate Polymers, vol. 42, no. 2, pp. 159-174, 2000.

[16] Y. Chen, M.-L. Liao, D. V. Boger, and D. E. Dunstan, "Rheological characterisation of $\kappa$-carrageenan/locust bean gum mixtures," Carbohydrate Polymers, vol. 46, no. 2, pp. 117-124, 2001.

[17] B. H. Bharatkumar, R. Narayanan, B. K. Raghuprasad, and D. S. Ramachandramurthy, "Mix proportioning of high performance concrete," Cement \& Concrete Composites, vol. 23, no. 1, pp. 71$80,2001$.

[18] E. Yilmaz, M. Benzaazoua, T. Belem, and B. Bussière, "Effect of curing under pressure on compressive strength development of cemented paste backfill," Minerals Engineering, vol. 22, no. 9-10, pp. 772-785, 2009.

[19] S. Ouellet, B. Bussière, M. Mbonimpa, M. Benzaazoua, and M. Aubertin, "Reactivity and mineralogical evolution of an underground mine sulphidic cemented paste backfill," Minerals Engineering, vol. 19, no. 5, pp. 407-419, 2006.

[20] M. Fall, M. Benzaazoua, and E. G. Saa, "Mix proportioning of underground cemented tailings backfill," Tunnelling and Underground Space Technology, vol. 23, no. 1, pp. 80-90, 2008.

[21] B. Ercikdi, A. Kesimal, F. Cihangir, H. Deveci, and İ. Alp, "Cemented paste backfill of sulphide-rich tailings: importance of binder type and dosage," Cement and Concrete Composites, vol. 31, no. 4, pp. 268-274, 2009.

[22] M. Fall and M. Benzaazoua, "Modeling the effect of sulphate on strength development of paste backfill and binder mixture optimization," Cement and Concrete Research, vol. 35, no. 2, pp. 301-314, 2005.

[23] S. Yin, A. Wu, K. Hu, Y. Wang, and Y. Zhang, "The effect of solid components on the rheological and mechanical properties of cemented paste backfill," Minerals Engineering, vol. 35, pp. 6166, 2012.

[24] B. Ercikdi, G. Külekci, and T. Yilmaz, "Utilization of granulated marble wastes and waste bricks as mineral admixture in cemented paste backfill of sulphide-rich tailings," Construction and Building Materials, vol. 93, pp. 573-583, 2015.

[25] P. K. Mehta, "First international conference on fly ash, silica fume, slag and other minerals by-products in concrete," ACI Publication SP-79, vol. I, pp. 1-46, 1983.

[26] D. Simon, Microscale Analysis of Cemented Paste Backfill, Department of Civil Engineering, University of Toronto, Toronto, Canada, 2005.

[27] K. Klein and D. Simon, "Effect of specimen composition on the strength development in cemented paste backfill," Canadian Geotechnical Journal, vol. 43, no. 3, pp. 310-324, 2006.
[28] B. Ercikdi, A. Kesimal, F. Cihangir, H. Deveci, and I. Alp, "Cemented paste backfill of sulphide-rich tailings: importance of binder type and dosage," Cement and Concrete Composites, vol. 31, no. 4, pp. 268-274, 2009.

[29] A. Tarig and M. Nehdi, "Developing durable paste backfill from sulphidic tailings," Waste and Resource Management, vol. 160, no. 4, pp. 155-166, 2007. 

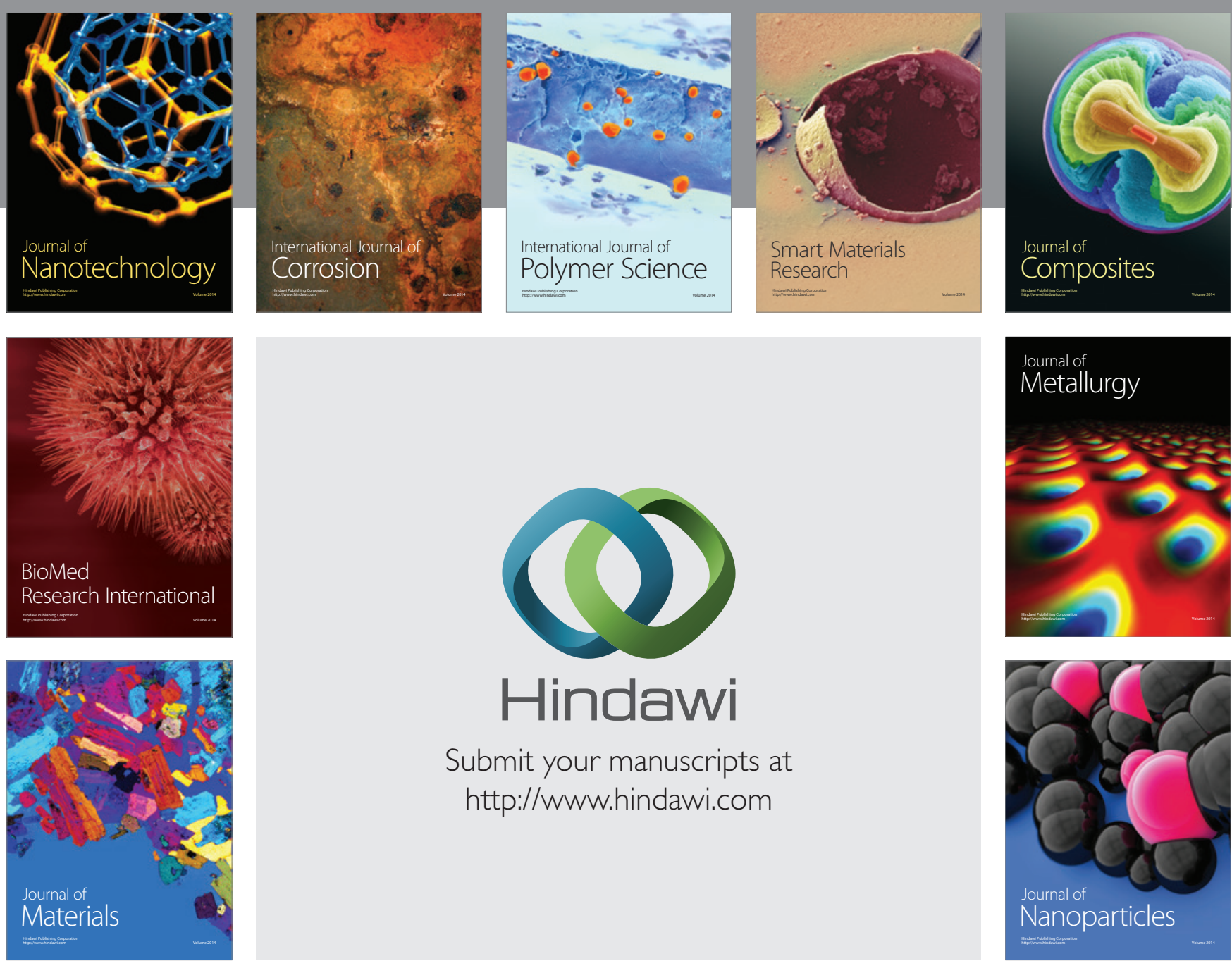

\section{Hindawi}

Submit your manuscripts at

http://www.hindawi.com

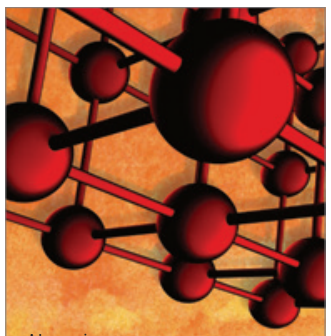

Materials Science and Engineering
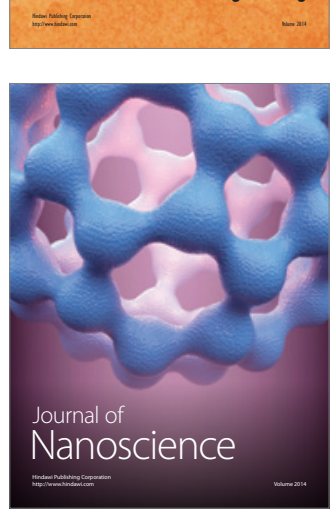
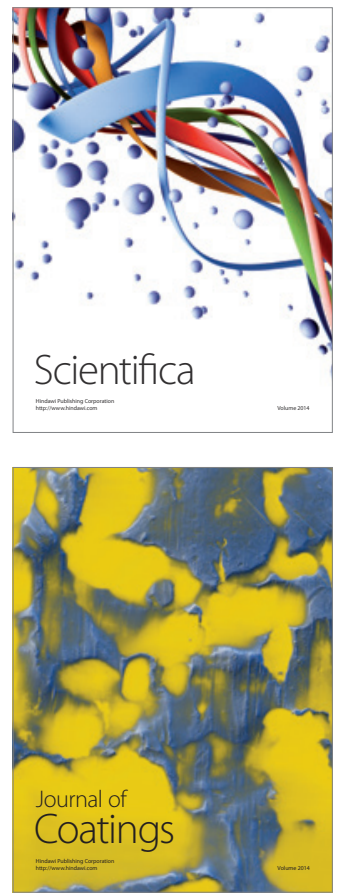
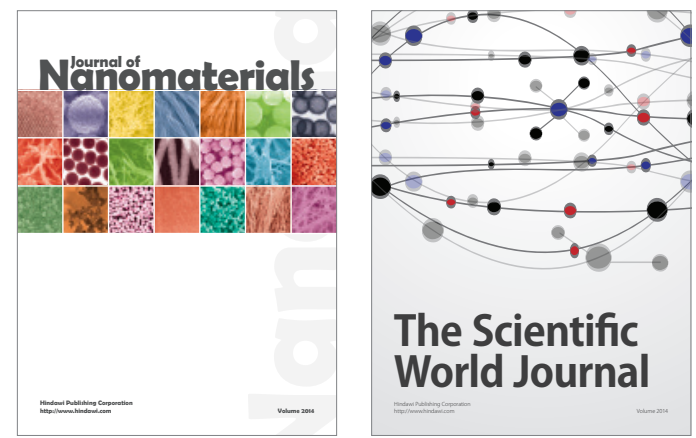

The Scientific World Journal
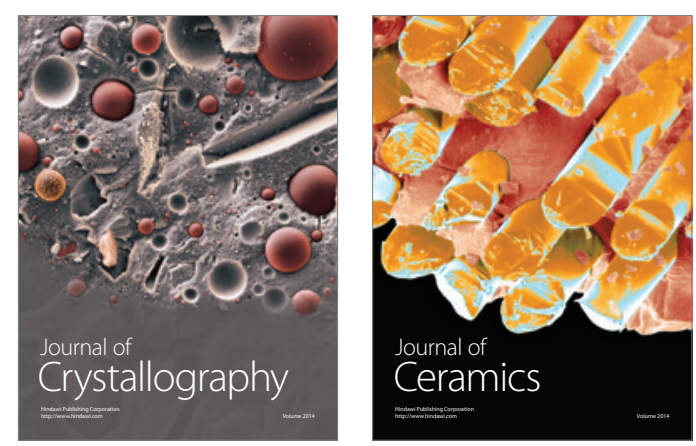
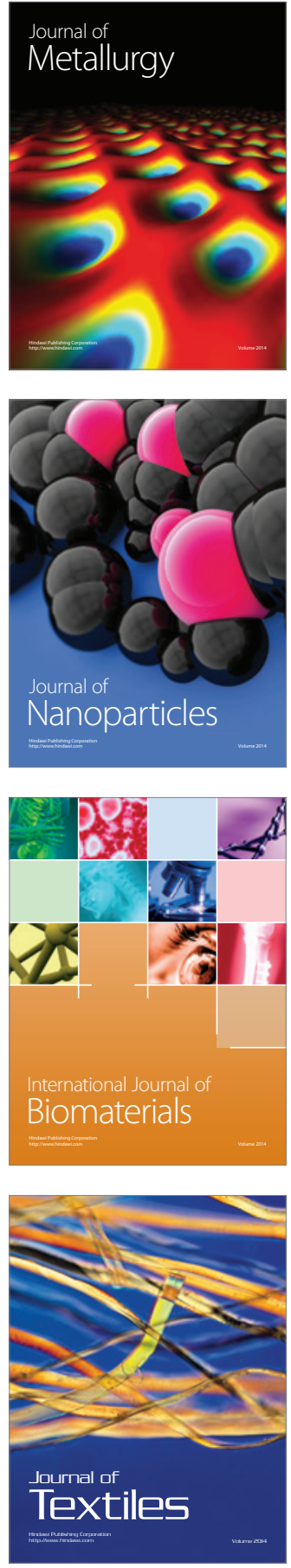